\title{
Hepatoprotective Effects of Phloridzin on Hepatic Fibrosis Induced by Carbon Tetrachloride against Oxidative Stress-Triggered Damage and Fibrosis in Rats
}

\author{
Gaigai Deng, ${ }^{a}$ Junzhi Wang, ${ }^{a}$ Qiaoyin Zhang, ${ }^{a}$ Haibo He, ${ }^{*}, a$ Fangfang Wu, ${ }^{a}$ Tianyan Feng, ${ }^{a}$ \\ Jigang Zhou, ${ }^{b}$ Kun Zou, ${ }^{a}$ and Masao Hattori ${ }^{c}$ \\ ${ }^{a}$ Hubei Key Laboratory of Natural Products Research and Development, China Three Gorges University; ${ }^{b}$ Tradi- \\ tional Chinese Medicine Clinical Hospital of China, Three Gorges University; Yichang 443002, P. R. China: and \\ ${ }^{c}$ Division of Metabolic Engineering, Institute of Natural Medicine, University of Toyama; 2630 Sugitani, Toyama \\ 930-0194, Japan. Received January 17, 2012; accepted April 16, 2012
}

The present study was to study the hepatoprotective effects of phloridzin (PHL) on hepatic fibrosis induced by carbon tetrachloride $\left(\mathrm{CCl}_{4}\right)$ in rats, on the basis of this investigation, the possible mechanism of PHL was elucidated. Male Sprague Dawley (SD) rats were randomly divided into six groups: control, model, PHL-L, PHL-M, PHL-H and colchine. All rats except control group were intraperitoneally injected with $\mathrm{CCl}_{4}$, and control rats were injected with olive oil, twice a week for eight weeks. At the same time, the rats were orally given homologue drugs once a day, respectively. Hepatoprotective effects of PHL were evaluated by liver weight indexes, biochemical values, total antioxidant capacity and total-superoxide dismutase, histopathological observations, hepatic fibrosis, and the hepatic fibrosis relative gene and protein expressions. PHL significantly improved hepatic function; remarkably decreased serum hyaluronic acid (HA), transforming growth factor- $\beta 1$ (TGF- $\beta 1$ ), aspartate aminotransferase (AST), alanine aminotransferase (ALT) and liver tissues hydroxyproline, malondialdehyde (MDA) levels, increased glutathione peroxidase (GSH-Px), totalantioxygen capacity (T-AOC) and total-superoxide dismutase (T-SOD) contents of liver tissues; Real-time polymerase chain reaction (PCR) and immunohisto-chemical results showed PHL might markedly reverse the up-regulated mRNA and protein expressions of the $\alpha$-smooth muscle actin (SMA), TGF- $\beta 1$ and tissue inhibitor of metalloproteinase-1 (TIMP1), up-regulate the matrix metalloproteinase-1 (MMP1) mRNA and protein expressions. Histopathological observations provided supportive evidence for biochemical analyses and the hepatic fibrosis relative gene and protein expressions, and with the dose of PHL increasing, the aforesaid improvement became more and more strong. The studies demonstrated that PHL exerted beneficially hepatoprotective effects on hepatic fibrosis induced by $\mathbf{C C l}_{4}$, mainly enhancing antioxidant capacity of liver organizations, reduce the level of lipid peroxidation induced by $\mathrm{CCl}_{4}$, and protect hepatocyte membranes from damage, and alleviate hepatic fibrosis.

Key words phloridzin; hepatic fibrosis; antioxidative; carbon tetrachloride

Hepatic fibrosis, a leading cause of morbidity and mortality, is among the most prevalent health problems worldwide, and its endstage consequence is hepatic cirrhosis, which is characterized by nodule formation and altered hepatic function. ${ }^{1)}$ However, hepatic fibrosis is also a dynamic and sophisticatedly regulated wound healing response to chronic hepatocellular injury. Accumulating evidence suggests that hepatic fibrosis is a reversible disease, therefore an effective treatment would probably prevent or reverse the hepatic fibrotic process. ${ }^{2)}$ In recent years, considerably clinical and experimental evidences show that oxidative stress caused by an imbalance between the oxidant and antioxidant systems of the body in favor of the oxidants should be a major apoptotic stimulus in the different types of acute and chronic liver injury and hepatic fibrosis. ${ }^{3)}$ Carbon tetrachloride $\left(\mathrm{CCl}_{4}\right)$ is a xenobiotic used extensively to induce oxidative stress. The rats treated with $\mathrm{CCl}_{4}$ are frequently used to produce an experimental model to study hepatic fibrosis. ${ }^{4)}$ Hepatic fibrosis induced by $\mathrm{CCl}_{4}$ is associated with the exacerbation of lipid peroxidation and the depletion of antioxidant status. ${ }^{5}$ Accordingly, successful antioxidant interventions, which to date has attracted intensive interests from investigators, offer insights into delaying or preventing occurrence and development of hepatic fibrosis, may be a potential and effective therapeutic strategy for prevention and treatment of hepatic fibrosis.

Phloridzin [PHL, 1-(2-(beta-D-glucopyranosyloxy)-4,6-dihydroxyphenyl)-3-(4-hydroxyphenyl)-propan-1-one], molecular formula: $\mathrm{C}_{12} \mathrm{H}_{24} \mathrm{O}_{10}$, molecular weight: 436.4 . The chemical structure is shown in Fig. 1, which is a dihydrochalcone glycoside and is mainly distributed in plants of Malus. ${ }^{6}$ At first, PHL was extracted from apple. In recent years, researchers have found that PHL content of Malus hupehensis and Lithocarpus iithoseifouus is higher than apples', 7 ) and proved to be the main bioactive principles, such as antioxidation, ${ }^{8)}$ hypoglycemic effect, ${ }^{9)}$ estrogenic and antiestrogenic activities, ${ }^{10)}$ and abundantly used in medical and cosmetics fields. ${ }^{11,12)}$ Recently, PHL is extensively used for digestive diseases, ${ }^{13)}$ although our previous studies demonstrated that PHL had protective effects on acute liver injury caused by $\mathrm{CCl}_{4}$ in a mouse, ${ }^{14)}$ the underlying mechanisms remain poorly understood especially for antioxidant and fibrosis. The goal of our present study was to further confirm PHL hepatoprotection, and evaluate that whether PHL attenuate oxidative stress and inhibit fibrosis in hepatic fibrosis injury rats induced by $\mathrm{CCl}_{4}$, based on these results, investigate the antioxidative and antifibrotic mechanisms involved. 


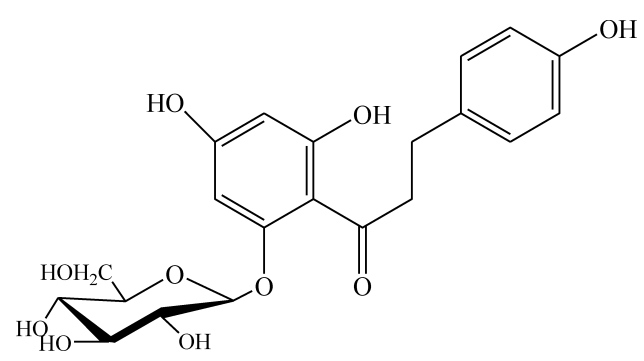

Fig. 1. Chemical Structure of PHL

\section{MATERIALS AND METHODS}

Materials The leaves of dried Malus hupehensis were supplied by Hubei Key Laboratory of Natural Products Research and Development, as authenticated by Dr. Kun Zou. The voucher specimens were deposited in Hubei Key Laboratory of Natural Products Research and Development, China Three Gorges University. PHL was isolated from the leaves of Malus hupehensis at a purity of more than $99.0 \%$.

Apparatus Image analysis system (Leica, Germany), PT1020 tissue processor and tissue slicer (Leica, Germany), Suprafuge 22 high speed refrigerated centrifuge (Heraeus instruments, Germany), $752 \mathrm{UV}$ and visible range microspectrophotometer (Shanghai, China), CDF-3220 Quantitative realtime polymerase chain reaction (MJ Research, U.S.A.).

Chemicals Colchine and $\mathrm{CCl}_{4}$ (Sigma-Aldrich Co., U.S.A.); aspartate aminotransferase (AST), alanine aminotransferase (ALT), hydroxy-proline (HYP), malondialdehyde (MDA), glutathione peroxidase (GSH-Px), total-antioxygen capacity (T-AOC) and total-superoxide dismutase (T-SOD) kits (Nanjing Jiancheng Bioengineering Institute, China); hyaluronic acid (HA), transforming growth factor- $\beta 1$ (TGF- $\beta 1$ ) enzyme-linked immunosorbent assay (ELISA) kits (R\&D systems, Inc., Minneapolis, U.S.A.); The monoclonal anti$\alpha$-smooth muscle actin (SMA) antibodies (Boster Biological Technology Co., Ltd., China); Monoclonal anti-matrix metalloproteinase-1 (MMP1), anti-tissue inhibitor of metalloproteinase-1 (TIMP1) and anti-horse-radish peroxidase (HRP)conjugated rabbit anti-mouse IgG secondary antibodies (Santa Cruz, CA, U.S.A.); The PrimeScript ${ }^{\circledR}$ RT Master Mix Kit (Dalian TaKaRa Biotechnology Co., Ltd., China). The THUNDERBIRD SYBR qPCR Mix kit (Osaka TOYOBO Co., Ltd., Japan). The primer sequences for PCR amplification (Shanghai Sangon Biotech Co., Ltd., China). other reagents were analytically pure.

Experimental Hepatic Fibrosis Male Wistar rats initially weighting 180-220g were purchased from the Laboratory Animal Institute of Hubei Disease Control Center, China. The rights of experimental animals were ensured quantum satis ad during the experiment. Rats were housed in constant conditions at a temperature of $23 \pm 3^{\circ} \mathrm{C}$, humidity of $60 \pm 5 \%$, and on a $12 \mathrm{~h}$ light-dark cycles. They were fed ad libitum and conditioned in a non-stressful environment for at least 1 week prior to experiments. Experiments were performed in accordance with the Guide for the Care and Use of Laboratory Animals of China Three Gorges University, and approved by the ethics committee. The whole laboratory procedure was carried out under the permission and surveillance of the ethics committee. The hepatic fibrosis model was performed according to a previous study. ${ }^{15)}$ Briefly, All rats except control group were intraperitoneally injected with $2 \mathrm{~mL} 50 \% \mathrm{CCl}_{4}$ which diluted in olive oil, while the control rats were given olive oil instead of $50 \% \mathrm{CCl}_{4}$, twice a day for 8 weeks, Phenobarbital induction was started $14 \mathrm{~d}$ before the first dose of $50 \% \mathrm{CCl}_{4}$ or olive oil at $350 \mathrm{mg} / \mathrm{L}$ in drinking water to increase liver sensitivity to $\mathrm{CCl}_{4}$.

Animal Treatment Schedule Animals were randomly divided into six groups: control; model; PHL-L (PHL, $20 \mathrm{mg}$ / $\mathrm{kg} / \mathrm{d}$, orally); PHL-M (PHL, $40 \mathrm{mg} / \mathrm{kg} / \mathrm{d}$, orally); PHL-H (PHL, $80 \mathrm{mg} / \mathrm{kg} / \mathrm{d}$, orally) and colchine $(2 \mathrm{mg} / \mathrm{kg} / \mathrm{d}$, orally), with 10 individuals in one group. Treatment of homologous drug was begun on the same time of model building, and vehicle was given to the control and model groups once a day for 8 weeks, and the experiment was carried out after the 8 th week.

Liver Index and Serum Biochemical Analysis After measuring body weight, the rats were anaesthetized with urethane $(1.2 \mathrm{~g} / \mathrm{kg}$, intraperitoneally (i.p.)), the blood samples from abdominal aorta were drawn into heparinized injectors, and the collected blood samples were centrifuged at $3000 \mathrm{rpm}$ at $4^{\circ} \mathrm{C}$ for $15 \mathrm{~min}$. Supernatant serums were transferred to clean EP tubes and stored at $-80^{\circ} \mathrm{C}$. Serum ALT and AST levels were measured by chemichromatometry according to the directions of the reagent kits. After finishing blood collection, the experimental animals were sacrificed, and livers were removed rapidly, washed with physiological saline and weighed, and then treated as described below.

Hepatic Homogenate Biochemical Analysis Hepatic homogenate were centrifuged at $3000 \mathrm{rpm}$ at $4^{\circ} \mathrm{C}$ for $15 \mathrm{~min}$. Supernatant homogenates were transferred to clean EP tubes and stored at $-80^{\circ} \mathrm{C}$. The MDA, GSH-Px, T-SOD and T-AOC levels in liver tissues were measured by chemichromatometry according to the directions of the reagent kits.

Hepatic HYP Content Analysis The content of hepatic HYP was determined by using the hydroxyproline kit following the protocol provided by the manufacturer.

ELISA Serum HA and TGF- $\beta 1$ were mesasured by using a rat $\mathrm{HA}$ and TGF- $\beta 1$ ELISA kits according to the manufacturer's instructions.

Histopathological Examination Liver tissues obtained from all experimental groups were fixed in $4 \%$ phosphatebuffered paraformaldehyde, and embedded in paraffin, sectioned at $4 \mu \mathrm{m}$, stained with hematoxylin and eosin (H\&E) for histopathological examination and with Masson's trichrome for assessment of fibrosis. ${ }^{16)}$ Sections were observed by using a Leica DM2500 microscope and image Leica analytical microsystems. Each sample was observed at a magnification of $200 \times$. The degree of hepatic fibrosis was expressed as the mean of five fields per section, and determined by a single investigator who was unware of the experimental groups.

Immunohistochemistry for $\alpha$-SMA, MMP1 and TIMP1 Immunohistochemistry of $\alpha$-SMA, MMP1 and TIMP1 were performed as follows: liver tissue sections were deparaffinized and the endogenous peroxidase was blocked with $\mathrm{H}_{2} \mathrm{O}_{2}$ for $10 \mathrm{~min}$. Then the sections were incubated with the monoclonal anti- $\alpha$-SMA antibody (1:500 dilution), monoclonal anti-MMP1 and TIMP1 antibody $\left(1: 400\right.$ dilution) at $4^{\circ} \mathrm{C}$ overnight. All antibodies were diluted in phosphate-buffered saline (PBS) containing bovine serum albumin (BSA), and PBS- $1 \%$ BSA as negative control. The sections were washed 
three times with PBS. Primary antibodies were detected with biotin-labeled anti-mouse immunoglobulin G (IgG). Counterstaining was performed with hematoxylin. At least five random fields of each section were examined at a magnification of $400 \times$, and semi-quantitative evaluations were assessed by a reader who was blinded to the animals' treatment status using a Photo and Image Autoanalysis System.

Quantitative Real-Time Polymerase Chain Reaction (Real-Time PCR) Analysis Total RNA of the hepatic muscles was extracted using TRIZOL reagent according to the supplier's instruction. RNA was quantitated by optical density measurement at 260 and $280 \mathrm{~nm}$ by using a spectrophotometer, and integrity was confirmed by running $4 \mu \mathrm{L}$ of RNA on a $1.5 \%$ agarose gel. RT (reverse transcription) was performed from total cellular RNA by using Revert Aid TM First-Strand cDNA Synthesis Kit for reverse transcriotion-polymerase chain reaction (RT-PCR); a total volume of $25 \mu \mathrm{L}$ reaction mixture containing $4.0 \mu \mathrm{g}$ of total RNA, $1.0 \mu \mathrm{L}$ of oligo-(dT) 18 $(0.5 \mu \mathrm{g} / \mu \mathrm{L})$ and $7.0 \mu \mathrm{L}$ of DEPC-treated water was denatured at $70^{\circ} \mathrm{C}$ for $5 \mathrm{~min}$ and chilled on ice for at least $1 \mathrm{~min}$. Subsequently, $4 \mu \mathrm{L}$ of $5 \times$ reaction buffer, $1.0 \mu \mathrm{L}$ RiboLock $^{\mathrm{TM}}$ ribonuclease inhibitor $(20 \mathrm{U} / \mu \mathrm{L})$ and $2.0 \mu \mathrm{L}$ deoxyribonucleotide triphosphate (dNTP) $(10 \mathrm{~mm})$ were mixed and incubated at $37^{\circ} \mathrm{C}$ for $5 \mathrm{~min}$. After incubation, $1.0 \mu \mathrm{L}$ MMLV Reverse Transcriptase $(200 \mathrm{U} / \mu \mathrm{L})$ was added and incubated at $37^{\circ} \mathrm{C}$ for $10 \mathrm{~min}, 42^{\circ} \mathrm{C}$ for $60 \mathrm{~min}$ and $70^{\circ} \mathrm{C}$ for $10 \mathrm{~min}$ in a thermocycler (Bio-Rad MJ Mini PCR, U.S.A.). Finally, samples were chilled on ice and incubated with $2 \mathrm{U}$ of RNase for $20 \mathrm{~min}$ at $37^{\circ} \mathrm{C}$ before amplifying the target cDNA. cDNA was quantified and assessed for purity using a UV spectrophotometer, and the concentration was measured at $260 \mathrm{~nm}$; the A260/ A280 relation was calculated to determine cDNA quality.

The PCR primers of $\alpha$-SMA, MMP-1, TIMP-1, TGF- $\beta 1$ and $\beta$-actin were synthesized by Shanghai Sangon Biotech Co., Ltd., China. The sequences of the primers used in this study were shown in Table 1. PCR was carried out in $20 \mu \mathrm{L}$ of reaction mixture containing $10 \mu \mathrm{L}$ of THUNDERBIRD SYBR qPCR Mix (Illumina, EC-100-1001, U.S.A.), $0.5 \mu \mathrm{L}$ $10 \mu \mathrm{M}$ of each forward and reverse primer, template cDNA and PCR-grade water up to a final volume of $25 \mu \mathrm{L}$ in a Bio-Rad iQ5 96-well plate. An initial activation at $95^{\circ} \mathrm{C}$ for $2 \mathrm{~min}$ was followed by an amplification target sequence of 40 cycles of pre-denaturing at $95^{\circ} \mathrm{C}$ for $60 \mathrm{~s}$, then $95^{\circ} \mathrm{C}$ for $15 \mathrm{~s}$, $60^{\circ} \mathrm{C}$ for $15 \mathrm{~s}$ and $72^{\circ} \mathrm{C}$ for $30 \mathrm{~s}$ in a thermocycler (CDF-3220 quantitative real-time PCR, U.S.A.). Polymerase chain reaction of $\beta$-actin chosen as an internal control was carried out in the same tubes as for the genes.

Statistical Analysis All data were expressed as mean \pm standard deviation (S.D.). Database was set up with SPSS 13.0 software package (SPSS Inc., Chicago, IL, U.S.A.). Differences among groups were analyzed by one-way analysis of variance (ANOVA). Post hoc testing was performed for inter-group comparisons using the least significant difference test (LSD). Resulting $p$ values less than 0.05 was regarded as statistically significant.

\section{RESULTS}

Effects of PHL on Body Weight Gain, Liver Index and Serum AST, ALT Levels In the model group, there were significantly decreased body weight gain compared with control group. PHL-H group body weight gain was markedly increased compared with model group $(p<0.01)$, but the body weight gain of the other groups did not remarkably differ; liver index in model group was significantly increased compared with the control group $(p<0.01)$; after treatment with PHL, there were different degree decrease, especially PHL$\mathrm{H}(p<0.05)$; In the the model group, the levels of AST and ALT were markedly decreased relative to the control group $(p<0.01)$, PHL markedly reversed these abnormal changes compared with the model group $(p<0.05$ and $p<0.01$, respectively), in the treated groups, the effect of PHL-H group was better (Table 2).

Effects of PHL on HYP Content in Liver Tissue and Serum HA Levels In the model group, HYP content in liver tissue and serum HA level were significantly increased compared with the control group $(p<0.01)$, PHL markedly attenuated all abnormalities of HYP and HA $(p<0.05$ and $p<0.01$,

Table 1. Primer Sequences Used in Quantitative Real-Time PCR

\begin{tabular}{lll}
\hline \hline Genes & \multicolumn{1}{c}{ Forward primer $\left(5^{\prime}-3^{\prime}\right)$} & Reverse primer $\left(5^{\prime}-3^{\prime}\right)$ \\
\hline$\alpha$-SMA & CCGAGATCTCACCGACTACC & TCCAGAGCGACATAGCACAG \\
MMP-1 & GCTGATACTGACACTGGTACTG & CAATCTTTTCTGGGAGCTC \\
TIMP-1 & GCAACTCCGGACCTTGTCATC & AGCGTAGGTCTTGGTGAAGC \\
TGF- $\beta 1$ & ACCGCAACAACGCAATCTATGAC & TGCTCCACAGTTGACTTGAATCTC \\
$\beta$-Actin & CTATCGGCAATGAGCGGTTCC & TGTGTTGGCATAGAGGTCTTTACG \\
\hline
\end{tabular}

Table 2. Effects of PHL on Body Weight Gain, Liver Index and Serum AST, ALT Levels in the Experimental Rats

\begin{tabular}{|c|c|c|c|c|c|}
\hline Group & $n$ & Body weight gain $(\mathrm{g})$ & Liver index $(\%)$ & AST (IU/L) & ALT (IU/L) \\
\hline Control & 10 & $93.1 \pm 8.5$ & $2.6 \pm 0.1$ & $12.32 \pm 6.04$ & $12.86 \pm 2.35$ \\
\hline Model & 6 & $-3.8 \pm 9.3 * *$ & $3.5 \pm 0.2 * *$ & $49.57 \pm 1.52 * *$ & $44.30 \pm 14.97 * *$ \\
\hline PHL-L & 7 & $1.23 \pm 6.9$ & $3.4 \pm 0.1$ & $34.76 \pm 3.41^{\#}$ & $35.77 \pm 5.49$ \\
\hline PHL-M & 9 & $-0.44 \pm 8.4$ & $3.3 \pm 0.1$ & $28.81 \pm 1.48^{\# \#}$ & $34.53 \pm 6.99$ \\
\hline PHL-H & 10 & $47.2 \pm 10.5^{\# \#}$ & $3.0 \pm 0.1^{\#}$ & $22.63 \pm 2.60^{\# \#}$ & $32.25 \pm 4.81$ \\
\hline Colchine & 6 & $-13.1 \pm 3.2$ & $3.4 \pm 0.1$ & $25.19 \pm 1.41^{\# \#}$ & $21.39 \pm 6.01^{\# \#}$ \\
\hline
\end{tabular}

PHL-L, PHL, $20 \mathrm{mg} / \mathrm{kg} / \mathrm{d}$; PHL-M, PHL, $40 \mathrm{mg} / \mathrm{kg} / \mathrm{d}$; PHL-H, PHL, $80 \mathrm{mg} / \mathrm{kg} / \mathrm{d}$; colchine, $2 \mathrm{mg} / \mathrm{kg} / \mathrm{d}$. Data are shown as the mean \pm S.D. $* * p<0.01 \mathrm{compared}$ with control group; ${ }^{\#} p<0.05,{ }^{\#} p<0.01$ compared with model group. 
respectively) compared with the model group, especially in the PHL-M and PHL-H groups (Table 3).

Effects of PHL on Antixoidant Assay in Liver Tissues Compromised hepatic functin is always associated with a state of oxidative stress in liver tissues and serum. Thus, the activities of the redox system were measured in liver tissues. Unusually changed activities of oxidant and antioxidant enzymens and the contents were found in the model group. Relative to the control group, decreased antioxidant activity of liver tissues was found in the reduced activities of GSH-Px (73.5\%, $p<0.01)$, T-SOD $(42.5 \%, p<0.01)$ and T-AOC $(68.2 \%$, $p<0.01)$ and increased MDA production $(264.7 \%, p<0.01)$, resectively, in the model rats. PHL markedly attenuated all abnormalities of oxidative stress $(p<0.05$ and $p<0.01$, respectively) compared with the model group, especially in the PHL$\mathrm{M}$ and PHL-H groups (Table 4).

Effects of PHL on Histopathological Changes and Quantification of Hepatic Fibrosis H\&E staining and Masson's trichrome staining showed the presence of hepatic injury and fibrosis, marked fatty degeneration, necrosis, inflammation of hepatocytes, and collagen accumulation in the model group (Figs. 2, 3); From the Fig. 3, we found that the collagen in model group was significantly increased compared with the control group $(p<0.01)$; after treatment with PHL, the collogen areas was significantly decreased compared with model group ( $p<0.01$, respectively), and there was dose-effect relationship among three PHL treated groups.

Effect of PHL on Serum TGF- $\beta 1$ and Its mRNA Levels in Liver Tissue In the model group, there were significantly increased serum TGF- $\beta 1$ and its mRNA level in liver tissue relative to the control group ( $p<0.01$, respectively); PHL markedly decreased all abnormalities of TGF- $\beta 1 \quad(p<0.05$ and $p<0.01$, respectively) compared with the model group, especially in the PHL-M and PHL-H groups (Fig. 4).

Effect of PHL on Hepatic Stellate Cells (HSCs)

Table 3. Effects of PHL on HYP Content in Liver Tissue and Serum HA Level of the Experimental Rats

\begin{tabular}{lrlc}
\hline \hline Group & $n$ & HYP $(\mu \mathrm{g} / \mathrm{g})$ & HA $(\mathrm{ng} / \mathrm{L})$ \\
\hline Control & 10 & $247 \pm 46$ & $30.34 \pm 5.47$ \\
Model & 6 & $663 \pm 90^{* *}$ & $59.18 \pm 4.18^{* *}$ \\
PHL-L & 7 & $547 \pm 64$ & $54 \pm 7.43$ \\
PHL-M & 9 & $304 \pm 57^{\# \#}$ & $43.06 \pm 8.10^{\# \#}$ \\
PHL-H & 10 & $265 \pm 47^{\# \#}$ & $46.68 \pm 6.37^{\# \#}$ \\
Colchine & 6 & $517 \pm 105$ & $41.60 \pm 7.33^{\# \#}$ \\
\hline
\end{tabular}

PHL-L, PHL, $20 \mathrm{mg} / \mathrm{kg} / \mathrm{d}$; PHL-M, PHL, $40 \mathrm{mg} / \mathrm{kg} / \mathrm{d}$; PHL-H, PHL, $80 \mathrm{mg} / \mathrm{kg} / \mathrm{d}$; colchine, $2 \mathrm{mg} / \mathrm{kg} / \mathrm{d}$. Data are shown as the mean \pm S.D. ${ }^{* *} p<0.01$ compared with control group; ${ }^{\prime \prime} p<0.01$ compared with model group.
Activated in the Liver Tissue $\alpha$-SMA was the marker of activated HSCs, whose positive expression was mostly found in the blood vessel wall of the control group. In model group, it was located in both fibrous septa and areas of inflammations. In contrast, treatment with PHL obviously attenuated the number of $\alpha$-SMA positive cells (Figs. 5C-E). In order to further confirm $\alpha$-SMA associated with HSCs, the $\alpha$-SMA mRNA and protein expression levels were detected by quantitative real-time $\mathrm{PCR}$ and immunohistochemistry. In the model group, the $\alpha$-SMA mRNA and protein levels were significantly increased compared with control group $(p<0.01$, respectively); After treated with PHL, these up-regulated tendencies of the $\alpha$-SMA mRNA and protein expressions were remarkably reversed compared with model group $(p<0.05$ and $p<0.01$, respectively), and with the dose of PHL progressively increasing, all of these changes became much stronger (Figs. $5 \mathrm{G}, \mathrm{H})$. The present results of the quantitative real-time PCR and immunohistochemistry studies provided effectively supportive evidence for the frontal histopathological changes and quantification of hepatic fibrosis analyses.

Effect of PHL on MMP1, TIMP1 mRNA and Protein Expressions in Liver Tissue In the control group, basal mRNA and protein expressions of MMP1 and TIMP1 were low. After induced by $\mathrm{CCl}_{4}$, the expression levels of MMP1 and TIMP1 appeared increased in different extent compared with control group $(p<0.01$, respectively), especially of TIMP1; In contrast, treatment with PHL further increased the expression levels of MMP1, and significantly decreased TIMP1 expression levels ( $p<0.01$, respectively), and the effect of PHL was stronger than colchine group (Figs. 6, 7).

\section{DISCUSSION}

In the present study, we demonstrated that PHL had beneficial effects on liver function in hepatic fibrosis model rats. These effects were in line with the improvments in decreasing collogen areas and hepatic fibrosis, suppressing oxidative stress-triggered damage, reverse the up-regulated mRNA and protein expressions of the $\alpha$-SMA, TGF- $\beta 1$ and TIMP1, up-regulate the MMP1 mRNA and protein expressions, and the meliorative effects of PHL presented in a dose-dependent manner. Hepatoprotective effects of PHL might result from scavenging oxidative stress- triggered damage and fibrosis. These results further confirmed the correlation among oxidative stress, hepatic injury and liver function as well as the recovery in dysfunction by suppressing oxidative stress and hepatic injury. ${ }^{3)}$

Hepatic fibrosis is thought to be a reversible disease; however, there is no satisfactory method in clinical

Table 4. Effects of PHL on Antioxidant Assay in the Liver Tissues of the Experimental Rats

\begin{tabular}{lrccll}
\hline \hline Group & $n$ & MDA (nmol/mg prot) & GSH-Px (U/mg prot) & T-SOD (U/mg prot) & T-AOC (U/mg prot) \\
\hline Control & 10 & $0.68 \pm 0.19$ & $16.35 \pm 3.25$ & $364.10 \pm 44.68$ & $1.32 \pm 0.14$ \\
Model & 6 & $2.48 \pm 0.52^{* *}$ & $4.34 \pm 2.93^{* *}$ & $209.27 \pm 38.44^{* *}$ & $0.42 \pm 0.12^{* *}$ \\
PHL-L & 7 & $2.02 \pm 0.75$ & $8.69 \pm 3.46^{\#}$ & $289.83 \pm 45.52$ & $0.69 \pm 0.24$ \\
PHL-M & 9 & $1.61 \pm 0.38^{\#}$ & $12.57 \pm 2.89^{\# \#}$ & $351.74 \pm 19.32^{\# \#}$ & $0.81 \pm 0.11^{\#}$ \\
PHL-H & 10 & $1.30 \pm 0.29^{\# \#}$ & $13.89 \pm 2.54^{\# \#}$ & $365.78 \pm 88.70^{\# \#}$ & $0.93 \pm 0.09^{\# \#}$ \\
Colchine & 6 & $1.63 \pm 0.57^{\#}$ & $9.25 \pm 3.05^{\# \#}$ & $277.77 \pm 50.49$ & $1.04 \pm 0.22^{\# \#}$ \\
\hline
\end{tabular}

PHL-L, PHL, $20 \mathrm{mg} / \mathrm{kg} / \mathrm{d}$; PHL-M, PHL, $40 \mathrm{mg} / \mathrm{kg} / \mathrm{d}$; PHL-H, PHL, $80 \mathrm{mg} / \mathrm{kg} / \mathrm{d}$; colchine, $2 \mathrm{mg} / \mathrm{kg} / \mathrm{d}$. Data are shown as the mean \pm S.D. $* * p<0.01 \mathrm{compared}$ with control group; ${ }^{\#} p<0.05,{ }^{\#} p<0.01$ compared with model group. 

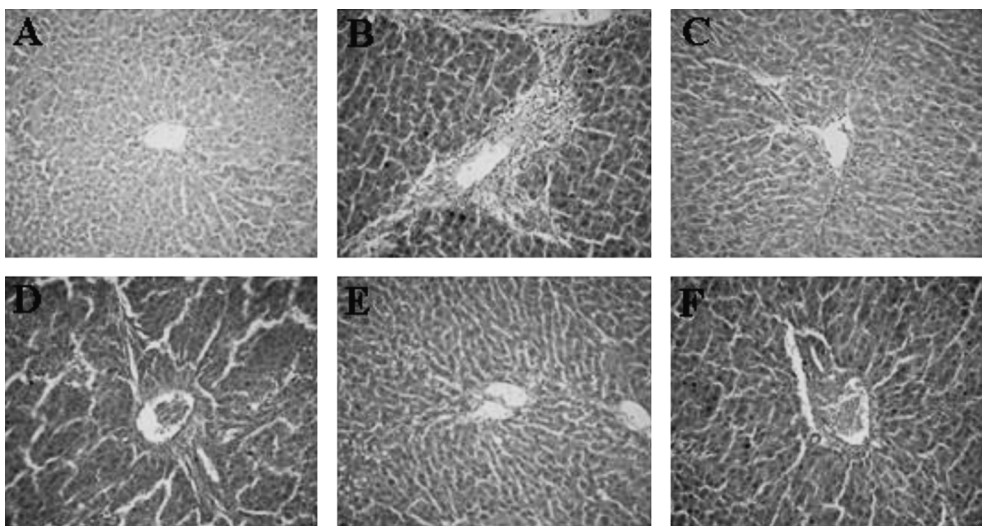

Fig. 2. The Representative Photomicrographs of Rat Liver Tissues with Hematoxylin and Eosin (200×) in the Experimental Rats

A) Control group; B) model group; C) PHL-L group (PHL, $20 \mathrm{mg} / \mathrm{kg} / \mathrm{d}$ ); D) PHL-M group (PHL, $40 \mathrm{mg} / \mathrm{kg} / \mathrm{d}$ ); E) PHL-H group (PHL, $80 \mathrm{mg} / \mathrm{kg} / \mathrm{d}$ ); F) colchine group (colchine, $2 \mathrm{mg} / \mathrm{kg} / \mathrm{d}$ ).
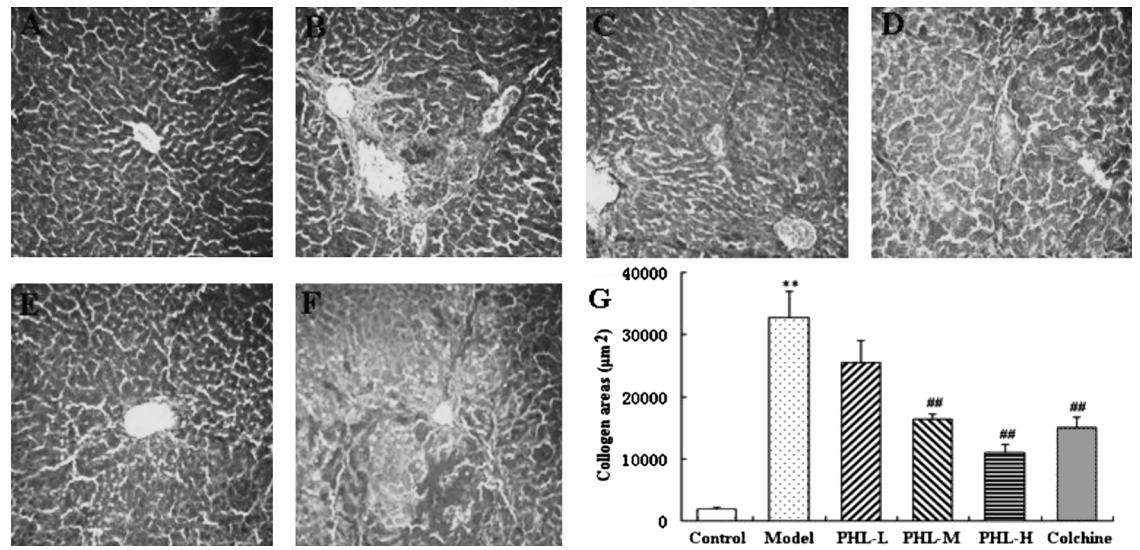

Fig. 3. The Representative Photomicrographs of Rat Liver Tissues with Masson Staining (200×) and Effect of PHL on the Hepatic Fibrosis in the Experimental Rats

A) Control group; B) model group; C) PHL-L group (PHL, $20 \mathrm{mg} / \mathrm{kg} / \mathrm{d}$ ); D) PHL-M group (PHL, 40 mg/kg/d); E) PHL-H group (PHL, $80 \mathrm{mg} / \mathrm{kg} / \mathrm{d}$ ); F) colchine group (colchine, $2 \mathrm{mg} / \mathrm{kg} / \mathrm{d}$ ); G) effect of PHL on the hepatic fibrosis in the experimental rats. Data are shown as the mean \pm S.D. $(n=6)$. ${ }^{* *} p<0.01$ compared with control group; $\# p<0.01$ compared with model group.
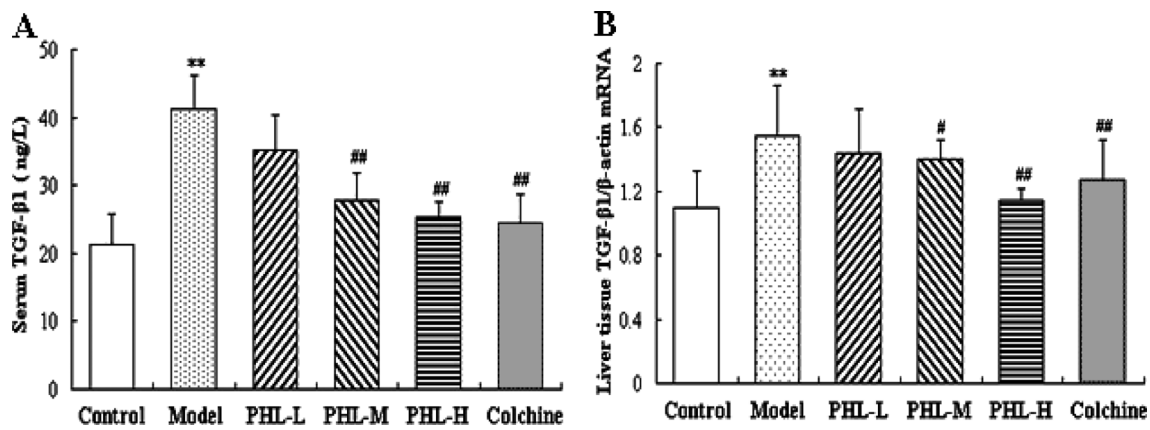

Fig. 4. Effects of PHL on Serum TGF- $\beta 1$ Content and Liver Tissue TGF- $\beta 1$ mRNA Level

A) Effect of PHL on serum TGF- $\beta 1$ content; B) effect of PHL on liver tissue TGF- $\beta 1$ mRNA level. Data are shown as the mean \pm S.D. $(n=6$ or 3$)$. ** $p<0.01$ compared with control group; ${ }^{\#} p<0.05,{ }^{\# \#} p<0.01$ compared with model group.

practice to reverse the pathological process. ${ }^{17)}$ In recent years, researchers ${ }^{18-20)}$ have found many traditional chinese drugs had a very good therapeutic effects in preventing fibrogenesis and other causes of chronic liver injury, which helps to develop a more hopeful future in controlling liver fibrosis injury and fibrosis. PHL is a mainly active monomer isolated from Malus hupehensis. Leaves of Malus hupehensis have been drunk as tea for 400 years, and are used for protecting liver from injury in Tujia nationality. ${ }^{13)}$

$\mathrm{CCl}_{4}$ is a well-known hepatotoxic chemical. The main cause of liver injury and fibtosis by $\mathrm{CCl}_{4}$ is free radicals of its metabolites. $\mathrm{CCl}_{4}$ generates methyltrichloride radicals $\left(\mathrm{CCl}_{3} \cdot\right)$, which are highly unstable and immediately react with cell membrane components, which break cell membrane integrity, and result in ALT, AST in cell plasma leak out. Therefore, serum ALT and AST are the most commonly used biochemical 

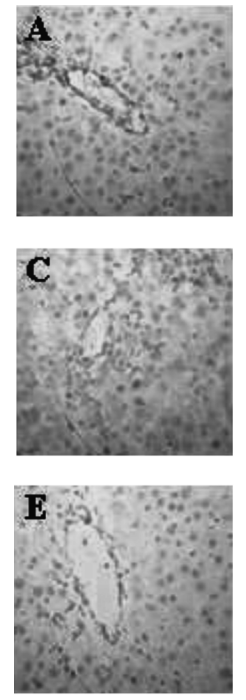
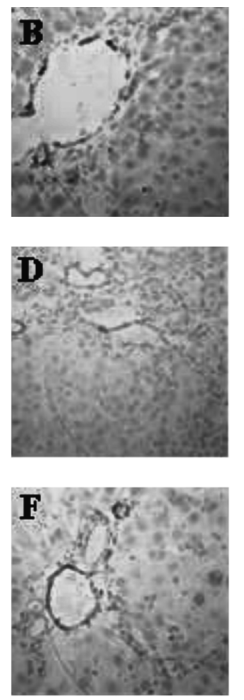

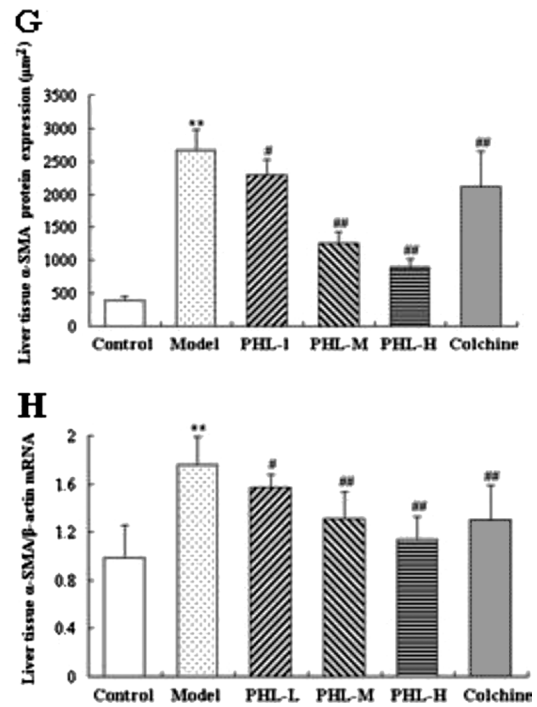

Fig. 5. The Representative Photomicrographs of Liver Tissues $\alpha$-SMA Immunohistochemistry (400×) and Effect of PHL on the Liver Tissue $\alpha$-SMA Protein and mRNA Expressions in the Experimental Rats

A) Control group; B) model group; C) PHL-L group (PHL, $20 \mathrm{mg} / \mathrm{kg} / \mathrm{d}$ ); D) PHL-M group (PHL, 40 mg/kg/d); E) PHL-H group (PHL, $80 \mathrm{mg} / \mathrm{kg} / \mathrm{d}$ ); F) colchine group (colchine, $2 \mathrm{mg} / \mathrm{kg} / \mathrm{d}$ ); G) effect of PHL on on the liver tissue $\alpha$-SMA protein expression; H) effect of PHL on the liver tissue $\alpha$-SMA mRNA expression. Data are shown as the mean \pm S.D. $(n=6$ or 3$)$. ${ }^{* *} p<0.01$ compared with control group; ${ }^{*} p<0.05,{ }^{\# \#} p<0.01$ compared with model group.
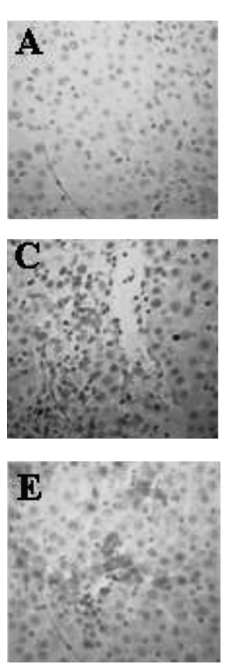
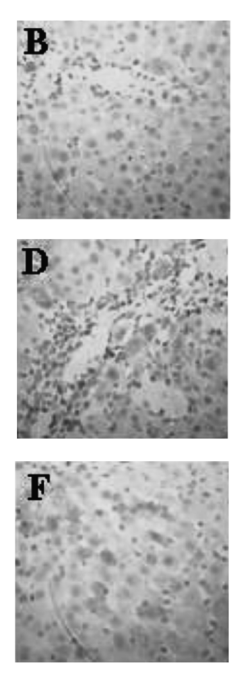

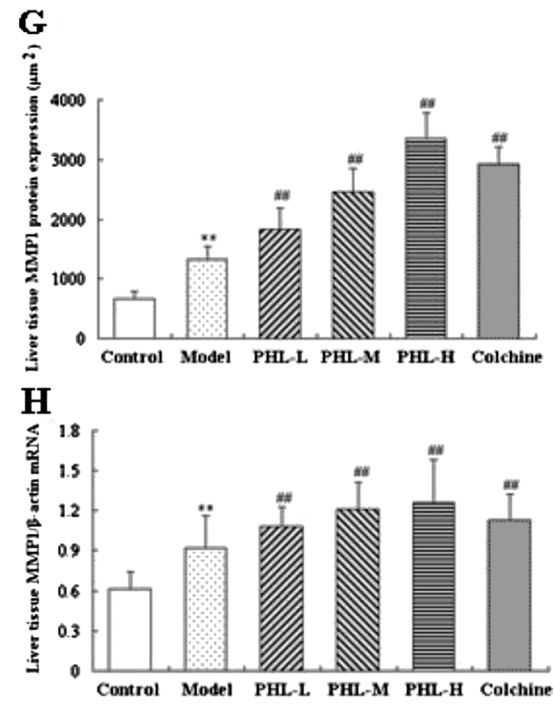

Fig. 6. The Representative Photomicrographs of Liver Tissue MMP1 Immunohistochemistry (400×) and Effect of PHL on the Liver Tissue MMP1 Protein and mRNA Expressions in the Experimental Rats

A) Control group; B) model group; C) PHL-L group (PHL, $20 \mathrm{mg} / \mathrm{kg} / \mathrm{d}$ ); D) PHL-M group (PHL, 40 mg/kg/d); E) PHL-H group (PHL, $80 \mathrm{mg} / \mathrm{kg} / \mathrm{d}$ ); F) colchine group (colchine, $2 \mathrm{mg} / \mathrm{kg} / \mathrm{d}$ ); G) effect of PHL on on the liver tissue MMP1 protein expression; H) effect of PHL on the liver tissue MMP1 mRNA expression. Data are shown as the mean \pm S.D. $(n=6$ or 3$) .{ }^{* *} p<0.01$ compared with control group; ${ }^{\# \#} p<0.01$ compared with model group.

markers of liver injuries. ${ }^{21)}$ In present study, we found that PHL could significantly decrease the activities of serum ALT and AST compare with the model group, which demonstrated that PHL had a significantly protective effect on liver injuries.

Usually, chronic liver injury may lead to development of fibrosis. During these processes, HSCs play a major role. The phenotype of activated HSCs is characterized by $\alpha$-SMA expression, which is recognized as being critical in liver fibrogenesis. ${ }^{22)}$ HYP is an amino acid found almost exclusively in collagens. Determination of HYP in liver tissues is regarded as a good method to quantify fibrosis, and to evaluate the effectiveness of new potentially antifibrotic agents. ${ }^{23)}$ In the liver, HA is synthesized and secreted by fatstoring cells. Its concentration in normal liver is low, but in fibrotic liver it shows both relative and absolute increases; consequently, serum HA level is regarded as a good mark for quantify fibrosis. ${ }^{24)}$ Our present study showed that the protein and mRNA expression levels of liver tissue $\alpha$-SMA, liver tissue HYP and serum HA significantly increased in the model group. PHL reduced $\alpha$-SMA mRNA and protein levels, and reduced liver tissue HYP content and serum HA level. The results demonstrate that PHL had the inhibition effects on hepatic fibrosis.

Increasing evidences show that oxidative stress contribute to the pathogenesis of various acute and chronic liver diseases. Reactive oxygen species (ROS) cause impairment of cellular membrane stability and cell death by lipid peroxidation. ${ }^{25}$ 

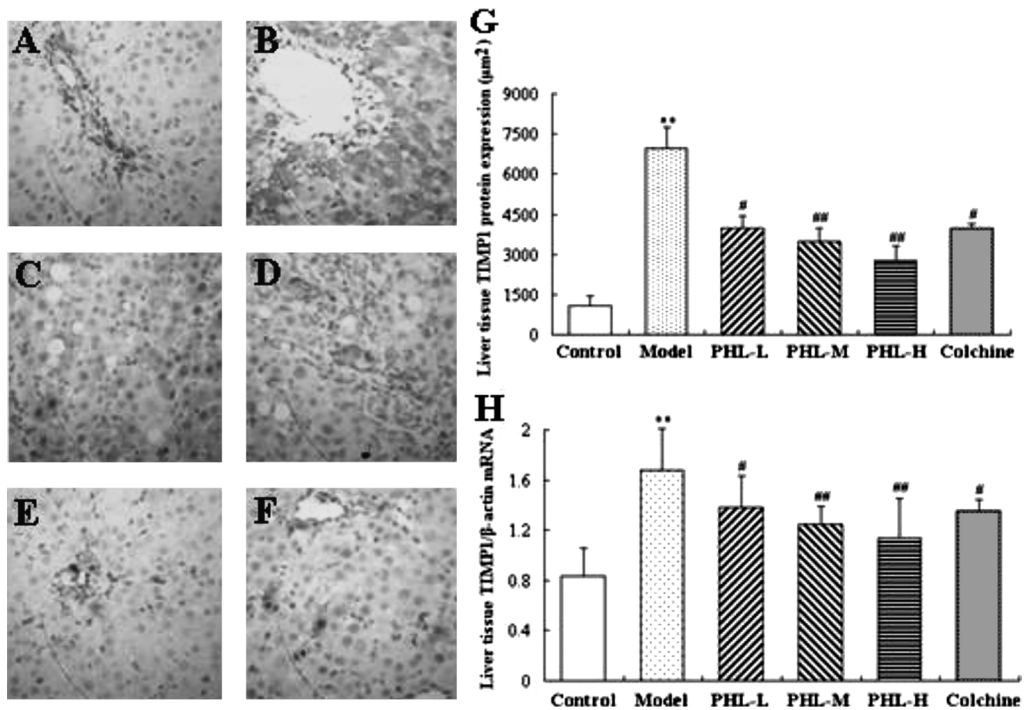

Fig. 7. The Representative Photomicrographs of Liver Tissue TIMP1 Immunohistochemistry $(400 \times)$ and Effect of PHL on the Liver Tissue MMP1 Protein and mRNA Expressions in the Experimental Rats

A) Control group; B) model group; C) PHL-L group (PHL, $20 \mathrm{mg} / \mathrm{kg} / \mathrm{d}$ ); D) PHL-M group (PHL, 40 mg/kg/d); E) PHL-H group (PHL, $80 \mathrm{mg} / \mathrm{kg} / \mathrm{d}$ ); F) colchine group (colchine, $2 \mathrm{mg} / \mathrm{kg} / \mathrm{d}$ ); G) effect of PHL on on the liver tissue TIMP1 protein expression; H) effect of PHL on the liver tissue TIMP1 mRNA expression. Data are shown as the mean \pm S.D. ( $n=6$ or 3$)$. ${ }^{* *} p<0.01$ compared with control group; ${ }^{\#} p<0.05,{ }^{\#} p<0.01$ compared with model group.

MDA was one of the main lipid peroxidation products, its elevated levels could reflect the degrees of lipid peroxidation injury in hepatocytes. ${ }^{26)}$ However, SOD is a scavenger of peroxide anion radicals, which could inhibit the initiation of lipid peroxidation by free radicals ${ }^{27)}$; GSH-Px could particularly catalyze the reductive action of $\mathrm{GSH}$ to $\mathrm{H}_{2} \mathrm{O}_{2}$ to protect the integrity of plasma membrane and functions. ${ }^{28)}$ Our present study showed that the content of MDA in liver homogenate increased in the model group, and the activities of T-SOD, T-AOC and GSH-Px decreased correspondingly. PHL markedly inhibited the increase of MDA level and up-regulated lower levels of the activities of T-SOD, T-AOC and GSH-Px in different extents. These results indicated that PHL had the hepatoprotective effects against lipid peroxidation.

Kupffer cells which could secrete TGF- $\beta 1$ are activated by lipid peroxidation products. TGF- $\beta 1$ inhibits production of the matrix-degrading enzymes, interstitial collagenase, stromelysin and plasmin by inhibiting of urokinase plasminogen activator, while simultaneously up-regulating expression of TIMP1 and plasminogen activator inhibitor. ${ }^{29-32)}$ Liver fibrosis, which is characterized by the excess deposition of extracellular matrix components, is usually the ultimate pathological outcome for the majority of chronic liver injuries. Central to the process of liver fibrosis is the activation of the HSC, which proliferates and stimulates the production and deposition of collagen. The activated HSC also express tissue inhibitors of TIMP1, which inhibits the degradation of interstitial collagens by interstitial collagenase such as MMP1. ${ }^{33-35)}$ In situations of spontaneous recovery from liver fibrosis, there is a diminution of TIMP expression and an increase in collagenase activity with consequent degradation of the collagen matrix. ${ }^{33)} \mathrm{Our}$ results showed that TGF- $\beta 1$ mRNA levels and serum TGF- $\beta 1$ protein levels in control group were low, while the expression levels of TGF- $\beta 1$ were converse in the model group. PHL might down-regulated TGF- $\beta 1$ mRNA expression levels in liver tissue, serum TGF- $\beta 1$ levels were the same as the change tendency of TGF- $\beta 1$ mRNA expression; after treatment with
PHL, mRNA and protein expression levels of TIMP1 in liver tissue were significantly down-regulated, while MMP1 were significantly up-regulated correspondingly. These findings implied that PHL down-regulated TGF- $\beta 1$ expression in vivo through antioxidative effect, and this effect perhaps was the main mechanism of inhibition effect on hepatic fibrosis. Which was in line with the effects of PHL on $\alpha$-SMA mRNA and protein expression levels, and histopathological changes and quantification of hepatic fibrosis analyses. These results also verified the foregoing hypothesis that PHL possessed the capacity to preserve the structural integrity of hepatocyte from the adverse effects of liver injury induced by $\mathrm{CCl}_{4}$.

\section{CONCLUSION}

In this study, all of the experimental results demonstrated that PHL exerted beneficially hepatoprotective effects on hepatic fibrosis induced by $\mathrm{CCl}_{4}$, mainly enhancing antioxidant capacity of liver organizations, reduce the level of lipid peroxidation induced by $\mathrm{CCl}_{4}$, and protect hepatocyte membranes from damage, and alleviate hepatic fibrosis. PHL was easy to extract, isolate and identify, so it also showed excellent prospects in the development of some new drugs for treating hepatic fibrosis.

Acknowledgement This study was supported by industry-university-research cooperation project from Education Department of Hubei (No: CXY2009B007).

\section{REFERENCES}

1) Pinzani M, Rombouts K. Liver fibrosis: from the bench to clinical targets. Dig. Liver Dis., 36, 231-242 (2004).

2) Iredale J. Defining therapeutic targets for liver fibrosis: Exploiting the biology of inflammation and repair. Pharmacol. Res., 58, 129-136 (2008).

3) Ghatak S, Biswas A, Dhali GK, Chowdhury A, Boyer JL, Santra A. 
Oxidative stress and hepatic stellate cell activation are key events in arsenic induced liver fibrosis in mice. Toxicol. Appl. Pharmacol., 251, 59-69 (2011).

4) Tsukamoto H, Matsuoka M, French SW. Experimental models of hepatic fibrosis: a review. Semin. Liver Dis., 10, 56-65 (1990).

5) $\mathrm{Fu} \mathrm{YM}$, Zheng SH, Lin JG, Ryerse J, Chen A. Curcumin protects the rat liver from $\mathrm{CCl}_{4}$-caused injury and fibrogenesis by attenuating oxidative stress and suppressing inflammation. Mol. Pharmacol., 73, 399-409 (2008).

6) Gosch C, Halbwirth H, Kuhn J, Miosic S, Stich K. Biosynthesis of phloridzin in apple (Malus domestica Borkh.). Plant Sci., 176, 223-231 (2009).

7) Fang R, Yang Q, Li L, Xiang JT, Wang JZ. The determination of the phloridzin contents in Malus hupehensis. Food Sci. Technol., 6, 195-196 (2008).

8) Vasantha Rupasinghe HP, Yasmin A. Inhibition of oxidation of aqueous emulsions of omega-3 fatty acids and fish oil by phloretin and phloridzin. Molecules, 15, 251-257 (2010).

9) Masumoto S, Akimoto Y, Oike H, Kobori M. Dietary phloridzin reduces blood glucose levels and reverses Sglt1 expression in the small intestine in streptozotocin-induced diabetic mice. J. Agric. Food Chem., 57, 4651-4656 (2009).

10) Wang JZ, Chung MH, Xue BJ, Ma H, Ma CM, Hattori M. Estrogenic and antiestrogenic activities of phloridzin. Biol. Pharm. Bull., 33, 592-597 (2010).

11) Ikumi Y, Kida T, Sakuma S, Yamashita S, Akashi M. Polymerphloridzin conjugates as an anti-diabetic drug that inhibits glucose absorption through the $\mathrm{Na}^{+}$/glucose cotransporter (SGLT1) in the small intestine. J. Control. Release, 125, 42-49 (2008).

12) Jung ES, Lee JS, Huh SR, Lee J, Kim YS, Kim G, Park D. Phloridzin-induced melanogenesis is mediated by the cAMP signaling pathway. Food Chem. Toxicol., 47, 2436-2440 (2009).

13) Zhang HQ, Wang JZ, Lu H, Zou K, Guo ZY, Wang XM. Protective effects of total flavonoids of Malus hupehensis (TFM) on animal liver injury. 2nd Int. Conf. on Natural Products and Traditional Medicine. pp. 256-260 (2010).

14) Feng TY, Fang R, Deng GG, Luo YC, Zou K, Chen JF, Xue BJ, Wang YQ, Wang JZ. Protective effect of phloridzin on acute liver injury induced by $\mathrm{CCl}_{4}$ in mice. Pharmacology and Clinics of Chinese Materia Medica, 26, 47-50 (2010).

15) Sun $\mathrm{H}$, Che QM, Zhao X, Pu XP. Antifibrotic effects of chronic baicalein administration in a $\mathrm{CCl}_{4}$ liver fibrosis model in rats. Eur. J. Pharmacol., 631, 53-60 (2010).

16) Hamza AA. Ameliorative effects of Moringa oleifera LAm seed extract on liver fibrosis in rats. Food Chem. Toxicol., 48, 345-355 (2010).

17) Weber SN, Wasmuth HE. Liver fibrosis: from animal models to mapping of human risk variants. Best Pract. Res. Clin. Gastroenterol., 24, 635-646 (2010).

18) Lou JL, Jiang MN, Li C, Zhou Q, He X, Lei HY, Li J, Jia YJ. Herb medicine Gan-fu-kang attenuates liver injury in a rat fibrotic model. J. Ethnopharmacol., 128, 131-138 (2010).

19) Mu YP, Liu P, Du GL, Du JX, Wang GQ, Long AH, Wang L, Li FH. Action mechanism of Yi Guan Jian Decoction on $\mathrm{CCl}_{4}$ induced cirrhosis in rats. J. Ethnopharmacol., 121, 35-42 (2009).

20) Peng WH, Tien YC, Huang CY, Huang TH, Liao JC, Kuo CL, Lin YC. Fraxinus rhynchophylla ethanol extract attenuates carbon tetrachloride-induced liver fibrosis in rats via down-regulating the expressions of uPA, MMP-2, MMP-9 and TIMP-1. $J$.
Ethnopharmacol., 127, 606-613 (2010).

21) Schindhelm RK, Diamant M, Dekker JM, Tushuizen ME, Teerlink T, Heine RJ. Alanine aminotransferase as a marker of non-alcoholic fatty liver disease in relation to type 2 diabetes mellitus and cardiovascular disease. Diabetes Metab. Res. Rev., 22, 437-443 (2006).

22) Carpino G, Morini S, Ginanni Corradini S, Franchitto A, Merli M, Siciliano M, Gentili F, Onetti Muda A, Berloco P, Rossi M, Attili AF, Gaudio E. Alpha-SMA expression in hepatic stellate cells and quantitative analysis of hepatic fibrosis in cirrhosis and in recurrent chronic hepatitis after liver transplantation. Dig. Liver Dis., 37, 349-356 (2005).

23) Zamara E, Novo E, Marra F, Gentilini A, Romanelli RG, Caligiuri A, Robino G, Tamagno E, Aragno M, Danni O, Autelli R, Colombatto S, Dianzani MU, Pinzani M, Parola M. 4-Hydroxynonenal as a selective pro-fibrogenic stimulus for activated human hepatic stellate cells. J. Hepatol., 40, 60-68 (2004).

24) Guéchot J, Laudat A, Loria A, Serfaty L, Poupon R, Giboudeau J. Diagnostic accuracy of hyaluronan and type III procollagen aminoterminal peptide serum assays as markers of liver fibrosis in chronic viral hepatitis $\mathrm{C}$ evaluated by ROC curve analysis. Clin. Chem., 42, 558-563 (1996)

25) Parola M, Robino G. Oxidative stress-related molecules and liver fibrosis. J. Hepatol., 35, 297-306 (2001).

26) Kim J, Chehade J, Pinnas JL, Mooradian AD. Effect of select antioxidants on malondialdehyde modification of proteins. Nutrition, $\mathbf{1 6}$, 1079-1081 (2000).

27) Cassani P, Beconi MT, O'Flaherty C. Relationship between total superoxide dismutase activity with lipid peroxidation, dynamics and morphological parameters in canine semen. Anim. Reprod. Sci., 86, 163-173 (2005).

28) Dolezych B, Szulinska E. Selenium modifies glutathione peroxidase activity and glutathione concentration in mice exposed to ozoneprovoked oxidative stress. J. Trace Elem. Med. Biol., 17, 133-137 (2003).

29) Branton MH, Kopp JB. TGF- $\beta$ and fibrosis. Microbes Infect., 1, 1349-1365 (1999).

30) Ciuclan L, Ehnert S, Ilkavets I, Weng HL, Gaitantzi H, Tsukamoto $\mathrm{H}$, Ueberham E, Meindl-Beinker NM, Singer MV, Breitkopf K, Dooley S. TGF- $\beta$ enhances alcohol dependent hepatocyte damage via down-regulation of alcohol dehydrogenase I. J. Hepatol., 52, 407-416 (2010).

31) Pohlers D, Brenmoehl J, Löffler I, Müller CK, Leipner C, SchultzeMosgau S, Stallmach A, Kinne RW, Wolf G. TGF- $\beta$ and fibrosis in different organs-molecular pathway imprints. Biochim. Biophys. Acta, 1792, 746-756 (2009).

32) Hemmann S, Graf J, Roderfeld M, Roeb E. Expression of MMPs and TIMPs in liver fibrosis - a systematic review with special emphasis on anti-fibrotic strategies. J. Hepatol., 46, 955-975 (2007).

33) Nakamuta M, Kotoh K, Enjoji M, Nawata H. Effects of fibril- or fixed-collagen on matrix metalloproteinase-1 and tissue inhibitor of matrix metalloproteinase-1 production in the human hepatocyte cell line HLE. World J. Gastroenterol., 11, 2264-2268 (2005).

34) Arthur MJP. Fibrogenesis II. Metalloproteinases and their inhibitors in liver fibrosis. Am. J. Physiol. Gastrointest. Liver Physiol., 279, G245-G249 (2000).

35) Guo Y, Wu XQ, Zhang C, Liao ZX, Wu Y, Wang H. Protective effect of sodium ferulate on acetaldehyde-treated precision-cut rat liver slices. J. Med. Food, 120309101825007 (2012). 